\title{
Gender and Editorial Outcomes at the American Political Science Review
}

\author{
Thomas König, University of Mannheim \\ Guido Ropers, University of Mannheim
}

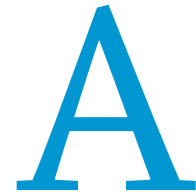

$s$ the premier outlet of the American Political Science Association (APSA), the American Political Science Review (APSR) understands itself as a journal of "general interest." The journal receives and publishes manuscripts from all disciplinary subfields of political science and related disciplines covering different types of research designs and methodologies. However, as with many other top political science journals, Teele and Thelen (2017) observe an underrepresentation of female authors in the APSR. They find that fewer than $23 \%$ of all authors in 634 articles published between 2000 and 2015 were female authors. In contrast, women make up about $31 \%$ of APSA-registered political scientists and around $40 \%$ of political science PhD students (Teele and Thelen 2017, 436). These numbers have raised discussion and underline previous findings on the distribution of female authors in published articles (Breuning and Sanders 2007; Evans and Moulder 2011; Østby et al. 2013).

Teele and Thelen (2017) discuss different explanations for this underrepresentation. They emphasize potential bias stemming from differences in publication rates that reflect differences in the composition of male and female scholars working within specific subfields or applying different methodological approaches. Moreover, they refer to the rise of coauthorship, which is particularly driven by all-male collaborations (Fisher et al. 1998). They raise attention to two competing explanations which apply in particular with respect to the discipline's top "generalist" journals: either women get rejected at higher rates or they are not submitting their research in the first place, possibly because of their expected higher rejection rate.

However, instead of focusing on published articles, one needs to study review processes to examine these explanations. With a rejection rate of around $95 \%$ of all manuscripts, the review process of the APSR has always been a matter of discussion-inside and outside of APSA. To select manuscripts for publication, the APSR applies a double-blind review process, which distinguishes between desk and reviewed rejections. It is noteworthy to mention that the new editorial team changed the process toward bilateral decision making between the lead editor and the responsible associate editor in August 2016. Among other things, this change aimed to reduce potential editor bias in particular subfields.

For the APSR, a first study by Breuning et al. (2018) looked at the acceptance rates from two years of data on corresponding authors, finding no indication for gender bias in the editorial process. Yet, corresponding authors may constitute a specific subgroup of authors, and as Teele and Thelen (2017) highlight, bias against female authors can arise at multiple stages in the editorial process: First, editors might be more likely to desk reject work by women. Second, male reviewers might be more negative in their evaluation of female-authored work, thereby biasing the editors' decision. Third, editors might be less likely to publish female work after it was sent out for review.

To provide empirical insights into the review process of the APSR and to examine potential gender bias in particular, we collected all available data from the review process of the past ten-year period between July 2007 and June 2017, covering a total of 8,386 submissions and 18,289 reviews. Besides collecting the gender not only of corresponding but of all the authors and reviewers, we extracted information on the type of authorship, subfield, and outcome (i.e., whether a manuscript was desk rejected or sent out for review, and in case of the latter, whether it was accepted for publication). For about $70 \%$ of all submissions, we also have information on each manuscript's methodological approach, distinguishing between quantitative and nonquantitative submissions.

Briefly summarized, our analysis shows a dominance of solo male submissions but no indication that approval rates are lower for female authors given their submission rates. Solo male authors have, in fact, the highest desk rejection rate. We also find that male reviewers are more likely to recommend rejection than female reviewers. Yet, it does not seem to influence the final outcome. As a journal of "general interest," we can also examine distributions of gender across subfields and methodological approaches for which we do not find substantial differences. Taken together, our analysis points much more to the problem of a systematically low submission rate of female authors as explanation for the underrepresentation of women in published articles in the APSR rather than to biases within the editorial process itself.

In spite of general female underrepresentation, we notice, however, an increasing number of submissions from and acceptances of female authors as well as of participation of female reviewers, as shown in figure 1 . Not shown here is that the share of collaboration between female and male authors is also increasing, whereas the share of solo male authors is decreasing. Both these trends correlate with an increasing share of females in the discipline. Nevertheless, the relative share of female authors published in our journal remains low.

The descriptive statistics of gender across editorial outcomes, subfields, and methodological approaches in table 1 provide more insights into the explanatory power of the subgroup hypotheses of Teele and Thelen (2017). Classified by the type of authorship, there is a comparatively high desk rejection rate of submissions 
by solo male authors on the one hand and a comparatively high share of male collaborative work among published papers on the other. Accordingly, we receive more male submissions, but male collaboration provides more success. In comparison, the share of solo female and team female papers remains astonishingly constant across outcomes, even though the share of collaboration among female authors is overall very low. With respect to subfield specificities, the distribution in Normative Theory differs strongly from other subfields and is characterized by a very high share of solo authors. This pattern also becomes apparent when we distinguish the submissions by methodological approach showing a much larger share of collaboration among quantitative submissions. According to Teele and Thelen (2017), a potential explanation for
Furthermore, collaborative work is less likely to be desk rejected regardless of the gender of the authors. Although quantitative work is more likely to be sent out than other approaches, there seems to be no difference between male and female authors. As the overall share of female authors among quantitative submissions $(26 \%$ in $2016-17)$ is similar to nonquantitative submissions (24\% in $2016-17)$, there is no indication that the higher desk rejection rate for nonquantitative submissions penalizes female authors, as hypothesized by Teele and Thelen (2017).

With regard to reviewer recommendations, collaborative work is more likely to receive positive feedback, again, independent of the authors' gender and controlling for subfield. As female reviewers seem to be less likely to recommend rejection, we also

\section{Taken together, our analysis points much more to the problem of a systematically low submission rate offemale authors as explanation for the underrepresentation of women in published articles in the APSR rather than to biases within the editorial process itself.}

gender bias is a tendency for journals to publish quantitative work presumably favoring male researchers. However, from looking at the descriptive statistics, no clear support for this thesis can be found. With Normative Theory, for example, the acceptance rate has been substantially above the submission rate in recent years, reaching a share of about 30\% in 2015 and 2016.

To draw more solid inferences about the role of gender in the review process of the APSR, we applied simple logit and ordered logit regression analyses to examine (1) the decision to send out a manuscript for review, (2) reviewer recommendations, and (3) the final editorial decision to publish a paper or not.

Concerning the decision to send out a manuscript for review, we find that the probability is lowest for solo male authors when controlling for subfield, editorial team, and quantitative approach, as indicated in table A1. When calculating first differences, the probability for solo male authors is 5.0 [2.5, 7.5] percentage points lower than for solo female authors, and $6.6[4.5,9.0]$ percentage points lower than for all-male teams. control whether this varies across authors' gender. Female reviewers seem to favor all female teams, although the simulated confidence intervals of the first difference to receive a reject recommendation by a female reviewer compared to both male reviewers $[-12.8,3.3]$ and all male team submissions [-9.3, 4.4 include zero. On closer inspection of subfields, reviewers from Normative Political Theory and Comparative Politics are more positive than reviewers from American Politics.

Finally for the editors' decision to publish a paper or not, there is no indication of discrimination against female authors. Furthermore, we do not find that editors follow reviewers' recommendations more depending on the authors' gender or that they treat female authors differently if they submit quantitative work as compared to nonquantitative work. This result is also reflected in the overall share of female authors among published articles which has fluctuated over the years but is on average about $24 \%$ for both quantitative and nonquantitative articles during our study period.

In sum, we do not find indication for systematic differences in publication success rates based on gender in the APSR review process that point toward editorial or reviewer biases against women. Despite small differences in the recommendations by male and female reviewers, this does not seem to bias the editors' decision whether or not a manuscript gets published. The diversity of submissions the APSR receives as a "general interest" journal, additionally, allowed us to examine differences across subfields and methodological approaches. However, none of these factors seems to result in a bias against the authors' gender.

It is important to stress, however, that our analysis does not 
allow us to conclude that gender bias does not exist in the $A P S R$. To do so, we lack objective information on the quality of manuscripts for similar manuscripts submitted by either male speaks much more in favor of the latter. As a consequence, if female authors in fact apply different standards than their male counterparts when deciding to submit a manuscript-for

\section{In comparison, the share of solo female and team female papers remains astonishingly constant across outcomes, even though the share of collaboration among female authors is overall very low.}

or female authors. Nevertheless, our results do not suggest that publication success differs systematically between authors' gender with the exception that the probability for desk rejection is much higher for solo male authors. If we assume that editors are able to objectively judge the quality of manuscripts at the desk rejection stage of the editorial process without discriminating against gender, it speaks in favor of a lower average quality of solo male submissions. It would hint to concerns that male and female authors have different quality reasons that might, for example, be related to their expectation to be discriminated against or different perceptions of the quality of their own work-analyses of editorial gender bias such as ours face the problem of sample selection bias. It makes it difficult to assess the degree of gender bias for manuscripts of the same quality, which future studies need to try to address.

On the positive side, we see an increasing trend toward collaboration, in particular of mixed gender teams. However,

If we assume that editors are able to objectively judge the quality of manuscripts at the desk rejection stage of the editorial process without discriminating against gender, it speaks in favor of a lower average quality of solo male submissions.

standards when submitting their work in the first place. With respect to the two competing explanations for gender bias raised by Teele and Thelen (2017), bias of editorial decisions and bias among the submissions a journal receives, this result a closer inspection of our analysis also reveals that women are less likely than men to be the first author when they act as the corresponding author. Out of the 1,504 submissions from mixed gender teams, in about $41 \%$ of the cases, women are the

Table 1

Editorial Outcomes, Subfield Submissions, and Methodological Approaches by Gender and Collaboration Type in the APSR, 2007-17

\begin{tabular}{|c|c|c|c|c|c|c|}
\hline & & Solo Male & Male Team & Mixed Team & Solo Female & Female Team \\
\hline & All Submissions & $39 \%$ & $27 \%$ & $18 \%$ & $13 \%$ & $3 \%$ \\
\hline \multirow[t]{3}{*}{ Outcome } & Desk Reject (23\%) & $53 \%$ & $19 \%$ & $12 \%$ & $14 \%$ & $2 \%$ \\
\hline & Revise and Reject (71\%) & $36 \%$ & $28 \%$ & $20 \%$ & $13 \%$ & $3 \%$ \\
\hline & Accept (6\%) & $34 \%$ & $33 \%$ & $18 \%$ & $12 \%$ & $3 \%$ \\
\hline \multirow[t]{8}{*}{ Subfield } & Comparative Politics (29\%) & $32 \%$ & $29 \%$ & $23 \%$ & $12 \%$ & $4 \%$ \\
\hline & American Politics (21\%) & $33 \%$ & $35 \%$ & $19 \%$ & $9 \%$ & $3 \%$ \\
\hline & IR (16\%) & $39 \%$ & $26 \%$ & $20 \%$ & $12 \%$ & $4 \%$ \\
\hline & Normative Theory (16\%) & $69 \%$ & $5 \%$ & $4 \%$ & $21 \%$ & $1 \%$ \\
\hline & Formal Theory (6\%) & $40 \%$ & $36 \%$ & $16 \%$ & $6 \%$ & $2 \%$ \\
\hline & Race \& Ethnicity (4\%) & $27 \%$ & $25 \%$ & $27 \%$ & $16 \%$ & $5 \%$ \\
\hline & Methodology (3\%) & $31 \%$ & $41 \%$ & $18 \%$ & $9 \%$ & $0 \%$ \\
\hline & Other (5\%) & $34 \%$ & $29 \%$ & $17 \%$ & $16 \%$ & $5 \%$ \\
\hline \multirow[t]{2}{*}{ Approach } & Quantitative (66\%) & $27 \%$ & $34 \%$ & $24 \%$ & $10 \%$ & $4 \%$ \\
\hline & Nonquantitative (33\%) & $57 \%$ & $15 \%$ & $9 \%$ & $18 \%$ & $2 \%$ \\
\hline
\end{tabular}

Note: For editorial outcomes, only manuscripts with a final decision and which were not withdrawn are included. Moreover, while the APSR editorial teams started to classify methodological approaches in July 2010, we lack the classification of 758 manuscripts before August 2016. 
corresponding authors. It roughly corresponds to their share among all authors in mixed gender teams, around $44 \%$. Out of these $41 \%$ of corresponding female authors, $72 \%$ are also first author. In contrast, the share is higher for male corresponding authors, who are in $79 \%$ of the cases also the first author of a manuscript. Thus, while more collaboration is clearly needed to increase the share of female authors, these numbers highlight the importance for collaboration among male and female authors to be conducted on equal terms.

\section{ACKNOWLEDGMENTS}

We thank our student assistants Ashrakat Elshehawy and Viktoria Semenova for assistance gathering the information on authors' and reviewers' gender. We thank Alyssa Taylor and Ben Lauderdale for helpful comments on earlier versions of this report.

\section{REF E RE N CES}

Breuning, Marijke, and Kathryn Sanders. 2007. "Gender and Journal Authorship in Eight Prestigious Political Science Journals." PS: Political Science \& Politics $40(2): 347-51$.

Breuning, Marijke, Benjamin Isaak Gross, Ayal Feinberg, Melissa Martinez, Ramesh Sharma,, and John Ishiyama. 2018. "Clearing the Pipeline? Gender and the Review Process at the American Political Science Review." PS: Political Science \& Politics doi: 10.1017/S1049096518000069.

Evans, Heather K., and A. Moulder. 2011. "Refiecting on a Decade of Women's Publications in Four Top Political Science Journals." PS: Political Science $\mathcal{E}$ Politics 44 (4): 793-98.

Fisher, Bonnie S., Craig T. Cobane, Thomas M. VanderVen, and Francis T. Cullen. 1998. "How Many Authors Does It Take to Publish an Article? Trends and Patterns in Political Science." PS: Political Science \& Politics 31 (4): 847-56.

Østby, Gudrun, Håvard Strand, Ragnhild Nordås, and Nils Petter Gleditsch. 2013 "Gender Gap or Gender Bias in Peace Research? Publication Patterns and Citation Rates for Journal of Peace Research, 1983-2008." International Studies Perspectives 14 (4): 493-506.

Teele, Dawn Langan, and Kathleen Thelen. 2017. "Gender in the Journals: Publication Patterns in Political Science." PS: Political Science \& Politics 50 (2): 433-47.

\section{Appendix}

Table A1

Regression Analyses of Editorial Outcomes in the APSR 2007-2017

\begin{tabular}{|c|c|c|c|c|c|c|}
\hline & Review Required & Reviewer Recommend. & Reviewer Recommend. & Accept & Accept & Accept \\
\hline Constant & $\begin{array}{l}0.79 * * * \\
(0.12)\end{array}$ & & & $\begin{array}{c}-11.58^{* * *} \\
(0.62)\end{array}$ & $\begin{array}{c}-11.71^{* * *} \\
(0.68)\end{array}$ & $\begin{array}{c}-13.40^{* * *} \\
(0.80)\end{array}$ \\
\hline Solo Female & $\begin{array}{c}0.43^{* * *} \\
(0.11)\end{array}$ & & $\begin{array}{l}-0.09 \\
(0.06)\end{array}$ & $\begin{array}{c}0.15 \\
(0.24)\end{array}$ & $\begin{array}{c}0.94 \\
(1.04)\end{array}$ & $\begin{array}{c}0.51 \\
(0.34)\end{array}$ \\
\hline Male Team & $\begin{array}{c}0.59 * * * \\
(0.10)\end{array}$ & & $\begin{array}{c}0.20 * * * \\
(0.04)\end{array}$ & $\begin{array}{c}0.20 \\
(0.20)\end{array}$ & $\begin{array}{l}-0.60 \\
(0.89)\end{array}$ & $\begin{array}{c}0.67 \\
(0.45)\end{array}$ \\
\hline Female Team & $\begin{array}{l}0.72^{* *} \\
(0.23)\end{array}$ & & $\begin{array}{l}-0.01 \\
(0.10)\end{array}$ & $\begin{array}{l}-0.46 \\
(0.45)\end{array}$ & $\begin{array}{c}1.83 \\
(1.54)\end{array}$ & $\begin{array}{l}-1.16 \\
(1.33)\end{array}$ \\
\hline Mixed Team & $\begin{array}{l}0.79^{* * * *} \\
(0.11)\end{array}$ & & $\begin{array}{l}0.10 * \\
(0.05)\end{array}$ & $\begin{array}{c}0.17 \\
(0.22)\end{array}$ & $\begin{array}{l}-0.67 \\
(1.02)\end{array}$ & $\begin{array}{l}-0.16 \\
(0.65)\end{array}$ \\
\hline Comparative Politics & $\begin{array}{c}0.03 \\
(0.11)\end{array}$ & $\begin{array}{l}0.17 * * * \\
(0.04)\end{array}$ & $\begin{array}{l}0.17 * * * \\
(0.04)\end{array}$ & $\begin{array}{l}0.52^{*} \\
(0.21)\end{array}$ & $\begin{array}{l}0.50 * * \\
(0.18)\end{array}$ & $\begin{array}{l}0.64^{*} \\
(0.25)\end{array}$ \\
\hline Formal Theory & $\begin{array}{l}0.58^{* *} \\
(0.18)\end{array}$ & $\begin{array}{l}-0.10 \\
(0.07)\end{array}$ & $\begin{array}{l}-0.11 \\
(0.07)\end{array}$ & $\begin{array}{l}-0.31 \\
(0.45)\end{array}$ & $\begin{array}{l}-0.01 \\
(0.34)\end{array}$ & $\begin{array}{l}-0.91 \\
(0.60)\end{array}$ \\
\hline International Relations & $\begin{array}{l}-0.14 \\
(0.12)\end{array}$ & $\begin{array}{l}-0.02 \\
(0.05)\end{array}$ & $\begin{array}{l}-0.01 \\
(0.05)\end{array}$ & $\begin{array}{c}0.19 \\
(0.26)\end{array}$ & $\begin{array}{c}0.15 \\
(0.23)\end{array}$ & $\begin{array}{c}0.29 \\
(0.31)\end{array}$ \\
\hline Methodology & $\begin{array}{c}0.02 \\
(0.21)\end{array}$ & $\begin{array}{l}-0.04 \\
(0.09)\end{array}$ & $\begin{array}{l}-0.06 \\
(0.09)\end{array}$ & $\begin{array}{c}0.38 \\
(0.43)\end{array}$ & $\begin{array}{c}0.40 \\
(0.40)\end{array}$ & $\begin{array}{l}1.17^{*} \\
(0.48)\end{array}$ \\
\hline Normative Political Theory & $\begin{array}{l}0.65^{* * *} \\
(0.14)\end{array}$ & $\begin{array}{l}0.47^{* * * *} \\
(0.05)\end{array}$ & $\begin{array}{c}0.56^{* * * *} \\
(0.05)\end{array}$ & $\begin{array}{c}0.19 \\
(0.33)\end{array}$ & $\begin{array}{c}0.29 \\
(0.22)\end{array}$ & $\begin{array}{c}0.30 \\
(0.39)\end{array}$ \\
\hline Other & $\begin{array}{l}-0.82 \\
(0.18)\end{array}$ & $\begin{array}{l}-0.22^{*} \\
(0.09)\end{array}$ & $\begin{array}{l}-0.21^{*} \\
(0.09)\end{array}$ & $\begin{array}{l}-0.65 \\
(0.80)\end{array}$ & $\begin{array}{l}-1.17 \\
(0.71)\end{array}$ & $\begin{array}{l}-0.61 \\
(0.89)\end{array}$ \\
\hline Race, Ethnicity, and Politics & $\begin{array}{l}-0.09 \\
(0.20)\end{array}$ & $\begin{array}{l}-0.04 \\
(0.08)\end{array}$ & $\begin{array}{l}-0.05 \\
(0.08)\end{array}$ & $\begin{array}{l}-0.29 \\
(0.48)\end{array}$ & $\begin{array}{l}-0.33 \\
(0.44)\end{array}$ & $\begin{array}{l}-0.44 \\
(0.60)\end{array}$ \\
\hline UNT & $\begin{array}{c}-0.27^{* *} \\
(0.09)\end{array}$ & & & $\begin{array}{l}-0.26 \\
(0.15)\end{array}$ & $\begin{array}{c}0.09 \\
(0.14)\end{array}$ & $\begin{array}{l}0.41^{*} \\
(0.21)\end{array}$ \\
\hline MA/LSE/COL & $\begin{array}{c}-1.79 * * * \\
(0.11)\end{array}$ & & & $\begin{array}{c}-1.43^{* *} \\
(0.49)\end{array}$ & $\begin{array}{c}-0.98^{*} \\
(0.47)\end{array}$ & $\begin{array}{l}-0.76 \\
(0.52)\end{array}$ \\
\hline Quantitative Approach & $\begin{array}{c}1.07 * * * \\
(0.09)\end{array}$ & & & $\begin{array}{l}-0.14 \\
(0.26) \\
\end{array}$ & & $\begin{array}{c}0.06 \\
(0.39) \\
\end{array}$ \\
\hline Female Reviewer & & $\begin{array}{l}0.07 * \\
(0.03)\end{array}$ & $\begin{array}{l}-0.00 \\
(0.06)\end{array}$ & & & \\
\hline Female Reviewer * Solo Female & & & $\begin{array}{c}0.19 \\
(0.10)\end{array}$ & & & \\
\hline
\end{tabular}


Table A1 (Continued)

\begin{tabular}{|c|c|c|c|c|c|c|}
\hline & Review Required & Reviewer Recommend. & Reviewer Recommend. & Accept & Accept & Accept \\
\hline Female Reviewer * Male Team & & & $\begin{array}{c}0.04 \\
(0.08)\end{array}$ & & & \\
\hline Female Reviewer * Female Team & & & $\begin{array}{l}0.51^{* *} \\
(0.16)\end{array}$ & & & \\
\hline Female Reviewer * Mixed Team & & & $\begin{array}{c}0.07 \\
(0.09)\end{array}$ & & & \\
\hline Number of Completed Reviews & & & & $\begin{array}{c}0.56^{* * * *} \\
(0.11)\end{array}$ & $\begin{array}{c}0.59 * * * \\
(0.10)\end{array}$ & $\begin{array}{c}0.69 * * * \\
(0.14)\end{array}$ \\
\hline Avg. Reviewer Recommend. & & & & $\begin{array}{c}4.04^{* * * *} \\
(0.18)\end{array}$ & $\begin{array}{c}3.70 * * * \\
(0.24)\end{array}$ & $\begin{array}{c}4.42^{* * *} \\
(0.22)\end{array}$ \\
\hline SD Recommend. & & & & $\begin{array}{c}-0.95^{* * *} \\
(0.18)\end{array}$ & $\begin{array}{c}-0.72 * * * \\
(0.16)\end{array}$ & $\begin{array}{c}-1.31^{* * *} \\
(0.22)\end{array}$ \\
\hline Solo Female * Avg. Recommend & & & & & $\begin{array}{r}-0.32 \\
(0.45)\end{array}$ & \\
\hline Male Team * Avg. Recommend & & & & & $\begin{array}{c}0.38 \\
(0.38)\end{array}$ & \\
\hline Female Team * Avg. Recommend & & & & & $\begin{array}{r}-0.92 \\
(0.65)\end{array}$ & \\
\hline Mixed Team * Avg. Recommend & & & & & $\begin{array}{c}0.39 \\
(0.44)\end{array}$ & \\
\hline Solo Female * quant. & & & & & & $\begin{array}{l}-0.79 \\
(0.58)\end{array}$ \\
\hline Male Team * quant. & & & & & & $\begin{array}{l}-0.76 \\
(0.53)\end{array}$ \\
\hline Female Team * quant. & & & & & & $\begin{array}{c}1.02 \\
(1.43)\end{array}$ \\
\hline Mixed Team * quant. & & & & & & $\begin{array}{c}0.12 \\
(0.71)\end{array}$ \\
\hline $\mathrm{AIC}$ & 5096.39 & 39103.69 & 39068.55 & 1406.95 & 1761.18 & 1059.76 \\
\hline $\mathrm{BIC}$ & 5196.32 & 39189.64 & 39217.01 & 1522.87 & 1902.50 & 1199.25 \\
\hline Log Likelihood & -2533.19 & -19540.84 & -19515.27 & -685.48 & -859.59 & -507.88 \\
\hline Deviance & 5066.39 & 39081.69 & 39030.55 & 1370.95 & 1719.18 & 1015.76 \\
\hline Num. obs. & 5779 & 18287 & 18287 & 4628 & 6183 & 4189 \\
\hline
\end{tabular}

${ }^{* * *} p<0.001,{ }^{* *} p<0.01,{ }^{*} p<0.05$. Reference categories: Solo Male; American Politics; UCLA Editorial Team 